Jurnal Keperawatan Silampari

Volume 4, Nomor 1, Desember 2020

e-ISSN: 2581-1975

p-ISSN: 2597-7482

DOI: https://doi.org/10.31539/jks.v4i1.1557

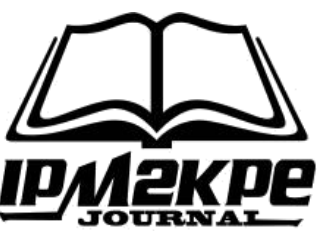

\title{
PENERAPAN SISTEM JAMINAN KESEHATAN NASIONAL PADA PELAYANAN KEBIDANAN DAN NEONATAL
}

\author{
Nelly Yuliana ${ }^{1}$, Hendra Setiawan ${ }^{2}$, Nyoman Anita Damayanti ${ }^{3}$ \\ Universitas Airlangga ${ }^{1,3}$ \\ Universitas Brawijaya ${ }^{2}$ \\ nelly.yuliana-2018@fkm.unair.ac.id ${ }^{1}$
}

\begin{abstract}
ABSTRAK
Tujuan dari penelitian ini untuk mendeskripsikan implementasi kebijakan dan regulasi Sistem Jaminan Kesehatan Nasional dalam pelayanan kebidanan dan neonatal di Kabupaten X, Provinsi Kalimantan Utara. Metode penelitian ini merupakan penelitian kualitatif dengan pendekatan deskriptif observasional. Hasil penelitian menunjukkan kendala dalam pelaksanaan sistem jaminan kesehatan nasional yaitu kurangnya informasi jaminan kesehatan nasional bagi bidan dan masyarakat serta tidak diterimanya pembayaran dana non kapitasi bagi bidan dalam sistem jaminan kesehatan nasional. Simpulan, sistem jaminan kesehatan nasional masih memerlukan banyak pembenahan yang masih diperlukan untuk kebijakan dan regulasi sistem jaminan kesehatan nasional baik di tingkat pusat maupun daerah, terutama dalam pelayanan kebidanan dan neonatal bagi bidan agar pelaksanaannya dapat berjalan dengan baik untuk menurunkan angka kematian ibu dan anak di Indonesia.
\end{abstract}

Kata Kunci: Dana Non Kapitasi, Pelayanan Kebidanan dan Neonatal, Sistem Jaminan Kesehatan Nasional

\begin{abstract}
The purpose of this study is to describe the implementation of policies and regulations of the National Health Insurance System in midwifery and neonatal services in $X$ District, North Kalimantan Province. This research method is a qualitative research with an observational descriptive approach. The results of the study show that there are obstacles in the implementation of the national health insurance system, namely the lack of information on national health insurance for midwives and the community and the non-acceptance of non-capitation funds for midwives in the national health insurance system. In conclusion, the national health insurance system still needs a lot of improvements that are still needed for policies and regulations of the national health insurance system both at the central and regional levels, especially in midwifery and neonatal services for midwives so that their implementation can run properly to reduce maternal and child mortality in Indonesia.
\end{abstract}

Keywords: Non-Capitation Fund, Midwifery and Neonatal Services, National Health Insurance System 


\section{PENDAHULUAN}

Penyelenggaraan sistem Jaminan Kesehatan Nasional (JKN) merupakan wujud komitmen pemerintah Indonesia terhadap kesehatan masyarakat. Melalui jaminan kesehatan nasional, pemerintah berharap masyarakat khususnya perempuan miskin dapat mengakses dan memperoleh pelayanan kesehatan yang terjangkau dan berkualitas tanpa mengeluarkan biaya. Namun demikian, penyelenggaraan sistem jaminan kesehatan nasional di Indonesia menghadapi berbagai kendala dan tantangan, baik dari pihak penyelenggara kesehatan, masyarakat sebagai pengguna, maupun pemerintah sebagai regulator program (Basuki et al., 2016).

Bidan sebagai salah satu tenaga kesehatan yang memberikan pelayanan kebidanan dan neonatal di fasilitas kesehatan tingkat pertama juga menghadapi berbagai kendala dalam penyelenggaraan jaminan kesehatan nasional, sehingga dibutuhkan banyak data, informasi dan solusi untuk meminimalisir kendala dan tantangan tersebut, karena akan mempengaruhi kinerja bidan di masa mendatang yang akan berkontribusi pada penurunan angka kematian ibu dan angka kematian bayi di Indonesia.

Beberapa kendala dapat dilihat berdasarkan penelitian terdahulu yang dilakukan Larasati et al., (2019) yang menunjukkan bahwa sebagian responden tidak mengikuti program Badan Penyelenggara Jaminan Sosial (BPJS) Kesehatan di Kabupaten Pasaman Barat Tahun 2018 yaitu sebesar 50\%. Menurut peneliti, ada beberapa faktor yang menyebabkan kurangnya minat bidan untuk bekerjasama dengan BPJS Kesehatan yaitu, terjadinya perubahan sistem pembiayaan tidak seperti pada saat Jampersal dimana semua ibu hamil dan melahirkan bisa mendapatkan pembiayaan pemerintah lewat Jamkesmas sehingga bidan praktek mudah bekerjasama dengan pemerintah. Pada era sistem JKN, bidan yang berpraktek mandiri saat ini belum bisa bekerjasama langsung dengan BPJS Kesehatan harus berjejaring dengan fasilitas kesehatan tingkat pertama (FKTP) yang mana pada saat pencairan akan ada pemotongan biaya administrasi dari pihak FKTP.

Berdasarkan penelitian yang dilakukan Raafiah (2018) menunjukkan bahwa seluruh informan (100\%) menyatakan bahwa klaim yang dibayarkan tidak setara dengan pekerjaan yang telah dilakukan bidan dan ada ketidaksesuaian besarnya tarif dipasaran umum terutama pada pelayanan Keluarga Berencana (KB) dan persalinan. Selain itu, ada pula keluhan dari bidan bahwa apabila ada kesalahan dalam pengajuan klaim, BPJS Kesehatan secara otomatis tidak mengganti klaim, tanpa mengkomunikasikan dengan bidan terlebih dahulu.

Penelitian sebelumnya sudah pernah dilakukan, namun pada penelitian ini menjelaskan permasalahan pembiayaan pelayanan kesehatan kebidanan dan neonatal di FKTP dan jaringan bidan dalam sistem pendanaan non kapitasi dalam sistem kesehatan nasional untuk upaya membantu menurunkan angka kematian ibu dan anak.

\section{METODE PENELITIAN}

Penelitian ini menggunakan penelitian kualitatif dengan pendekatan deskriptif observasi. Teknik pengambilan sampel dalam penelitian ini menggunakan purposive sampling. Purposive sampling digunakan untuk merekrut informan kunci. Partisipan dalam penelitian ini berjumlah 26 orang di Kabupaten X, Provinsi Kalimantan Utara, yang merupakan informan yang terlibat langsung atau dianggap memiliki kemampuan memahami permasalahan yang terjadi. Informan dalam penelitian ini meliputi 10 orang bidan jejaring, 8 bidan yang bekerja di Puskesmas, 5 orang Kepala Puskesmas, dan narasumber untuk kebijakan terpilih di Kabupaten $\mathrm{X}$ yaitu 1 orang Kepala Dinas 
Kesehatan, 1 orang Kepala Dinas Pendapatan Daerah dan 1 orang Kepala Kantor Badan Penyelenggara Jaminan Sosial (BPJS). Teknik pengumpulan data dengan wawancara semi terstruktur yang dilakukan secara tatap muka. Analisis data menggunakan metode dan teknik analisis tematik. Hasil analisis data dalam penelitian ini disajikan dengan menggunakan uraian naratif sesuai dengan fenomena yang ditemukan dalam wawancara semi terstruktur.

\section{HASIL PENELITIAN}

Dalam penelitian ini informan yang dipilih berjumlah 26 orang yang terlibat langsung dalam pembuatan kebijakan dan pelaksanaan program pelayanan kesehatan kebidanan dan neonatal di Kabupaten X Provinsi Kalimantan Utara.

Tabel. 1

Distribusi Frekuensi Jenis Kelamin dan Usia Informan

\begin{tabular}{lcc}
\hline Karakteristik & $\mathrm{n}$ & $\%$ \\
\hline Jenis kelamin & & \\
Laki-laki & 6 & $(23.0 \%)$ \\
Perempuan & 20 & $(77.0 \%)$ \\
Usia & & \\
$\leq 35$ tahun & 17 & $(65.4 \%)$ \\
$>35$ tahun & 9 & $(34.6 \%)$ \\
\hline
\end{tabular}

Hasil penelitian menunjukkan bahwa informan berjenis kelamin perempuan adalah yang paling banyak yaitu sebanyak 20 orang sedangkan kelompok usia yang paling banyak adalah $\leq 35$ tahun yaitu sebanyak 17 orang.

\section{Pengetahuan Bidan dalam Penyelenggaraan Sistem Jaminan Kesehatan Nasional}

Hasil penelitian mengenai pemahaman bidan terhadap sistem jaminan kesehatan nasional menunjukkan ada 8 informan yang juga merupakan staf Puskesmas dapat memberikan penjelasan tentang tujuan sistem jaminan kesehatan tetapi belum sepenuhnya memahami lebih dalam tentang sistem jaminan kesehatan nasional, khususnya yang berkaitan dengan pelayanan kebidanan dan neonatal. Hasil wawancara dengan salah satu informan sebagai berikut:

"Ya, saya ngerti tentang BPJS itu baik untuk ibu hamil, karena tujuan BPJS itu sepengetahuan saya bisa memenuhi kebutuhan kesehatan ibu hamil, mereka kan sudah bayar iurannya tiap bulan, ada juga yang dibayarkan sama pemerintah jadi mereka bisa periksa tanpa mikir biaya, dan ga (tidak) ragu-ragu untuk periksa, saya taunya ya gitu-gitu aja untuk yang lebih detail masih belum paham saya...”. (Bidan Puskesmas, wawancara \# 10).

Terdapat satu informan dari bidan praktik mandiri yang menyatakan belum pernah mendapatkan sosialisasi berkaitan dengan sistem jaminan kesehatan nasional. Informasi tentang sistem jaminan kesehatan nasional juga dirasakan masih kurang bagi masyarakat sehingga membuat bidan kesulitan menjelaskan tata cara atau prosedur pelayanan sistem jaminan kesehatan nasional kepada masyarakat. Berdasarkan hasil wawancara dengan 2 informan sebagai berikut: 
“...Belum mba, saya ga (tidak) pernah ikut sosialisasi di Puskesmas, saya tau tentang BPJS dikasi tau (diberitahu) temen-temen bidan juga...”. (Bidan jejaring, wawancara \# 2)

“...Pasien itu lho kadang ga tau tentang prosedur BPJS jadi kadang kita kesulitan untuk kasi tau (memberitahu) karena ga (tidak) terlalu paham juga tentang BPJS..." . (Bidan Puskesmas, wawancara \# 7).

Menurut pemegang polis Dinas Kesehatan, sosialisasi tentang sistem jaminan kesehatan nasional sudah dilakukan, namun tidak secara khusus membahas kebijakan mengenai pelayanan kebidanan dan neonatal. Berdasarkan hasil wawancara dengan salah satu informan sebagai berikut:

“...Sebenarnya sosialisasi tentang BPJS itu sudah dilaksanakan, memang undangannya tidak semua bidan bisa hadir hanya perwakilan dari masing-masing Puskesmas saja yang ikut, dan memang narasumber ga terlalu detail menyampaikan tentang tentang layanan kebidanan yang perlu diketahui saja...” (Kepala Dinas Kesehatan, wawancara \# 26).

Pengetahuan bidan kurang baik tentang paket jaminan kelahiran terutama tentang prosedur pelayanan akan tetapi berkemauan untuk menjadi penyedia layanan program jaminan kelahiran. Hal ini dikarenakan responden memiliki persepsi yang baik terhadap dan pembayaran dalam program paket jaminan kelahiran. Berdasarkan hasil wawancara dengan salah satu informan sebagai berikut:

"Saya rasa jampersal BPJS itu baik ya untuk ibu hamil yang kurang mampu, saya mau aja nolong persalinan menurut saya si pembayarannya sesuai lah, cuma masih ga ngerti gimana prosedur pelayanannya, maunya ada sosialisasi gitu biar ngerti ...”. (Bidan jejaring, wawancara \# 17).

\section{Persepsi Bidan tentang Tata Cara Administratif Pengurusan Klaim Dana Non Kapitasi Pelayanan Obstetri dan Neonatal dalam Sistem Jaminan Kesehatan Nasional}

Hasil wawancara tentang tata cara pengurusan klaim dana non kapitasi diperoleh informasi dari informan bahwa prosedur administrasi cukup rumit, mulai dari kuitansi, partograf, formulir penyerahan, fotokopi KTP, prosedur administrasi terkadang membuat bidan salah mengisi formulir klaim, prosedur administrasi klaim masih sulit karena harus ditulis tangan, fotokopi identitas, kuitansi, formulir dan syarat syarat pelaporan administrasi yang harus diberikan, seperti kuitansi, fotokopi identitas, buku KIA, foto ibu dan bayi dirasa terlalu rumit serta bidan masih mengalami kesalahan dalam pengisian berkas. Berdasarkan hasil wawancara dengan salah satu informan sebagai berikut:

“... wah rumit mba persyaratan administrasinya macam-macam, banyak temanteman sering salah isi juga berkasnya...”. (Bidan jejaring, wawancara \# 19).

\section{Persepsi Bidan tentang Proses Pelaksanaan Klaim Dana Non Kapitasi Pelayanan Obstetri dan Neonatal dalam Sistem Jaminan Kesehatan Nasional}

Hasil wawancara mengenai ketepatan waktu pelaksanaan klaim yang dilakukan dengan 16 bidan diperoleh informasi bahwa klaim yang diajukan bidan hingga ke BPJS bisa sampai 1 bulan lebih dan jika terjadi kesalahan pengajuan bisa sampai 2 bulan. 
Klaim bisa bertahan 1 sampai 2 bulan ini tidak sesuai dengan ketentuan aturan yaitu 15 hari kerja. Berdasarkan hasil wawancara dengan salah satu informan sebagai berikut:

"Iya betul mba klaimnya sudah diajukan berharapnya 15 hari udah beres tapi ini satu bulan baru kelar padahal ketentuannya itu ya 15 hari kerja, apalagi kalau ada salah berkas tambah lama bisa jadi dua bulan...". (Bidan jejaring, wawancara \# 14).

\section{Persepsi Bidan tentang Penerimaan Pembayaran Dana Non Kapitasi Pelayanan Obstetri dan Neonatal dalam Sistem Jaminan Kesehatan Nasional}

Hasil wawancara tentang penerimaan dana non kapitasi yang dilakukan dengan 16 bidan diketahui bahwa tidak ada dana yang diterima bidan meskipun sudah diklaim kepada BPJS yang melakukan pembayaran. Tidak adanya kepastian kapan klaim akan dibayarkan membuat bidan banyak mengeluh. Berdasarkan hasil wawancara dengan salah satu informan sebagai berikut:

"Uangnya ga cair-cair udah lama nunggu, banyak teman-teman juga ngeluh intinya si belum ada uangnya saya terima sampai sekarang”. (Bidan jejaring, wawancara \# 11).

Hasil wawancara Kepala Kantor BPJS Kabupaten X menyatakan bahwa klaim non kapitasi tentang pelayanan kebidanan dan neonatal telah dibayarkan tetapi BPJS membayarnya tidak secara langsung kepada bidan tetapi dibayarkan kepada Puskesmas. Berdasarkan hasil wawancara dengan salah satu informan sebagai berikut:

"Kami sudah membayar dana non kapitasi memang tidak secara langsung turun ke bidan tetapi sesuai aturan daerah dibayarkan Puskesmas jadi tanggung jawab kami sudah kami lakukan”. (Kepala Kantor BPJS, wawancara \# 23).

Hasil wawancara 5 Kepala Puskesmas Kabupaten X menyatakan bahwa dana non kapitasi yang telah dibayarkan oleh BPJS dimasukan semua ke dalam kas daerah sebagai pendapatan daerah atau retribusi sesuai peraturan daerah yang ada. Berdasarkan hasil wawancara dengan salah satu informan sebagai berikut:

"Mengenai dana non kapitasi sudah kami setor ke kas daerah, karena aturannya begitu, semua pendapatan Puskesmas harus diberikan semua ke pemerintah daerah sebagai pendapatan daerah atau retribusi daerah". (Kepala Puskesmas, wawancara \# 24).

Hasil wawancara Kepala Dinas Pendapatan Daerah Kabupaten X menyatakan bahwa dana non kapitasi yang telah dibayarkan oleh BPJS ke Puskesmas harus disetor semua ke dalam kas daerah sebagai pendapatan daerah yang akan dikembalikan ke Dinas Kesehatan sebagai anggaran kerja tahun berikutnya. Berdasarkan hasil wawancara dengan salah satu informan sebagai berikut:

"Dana non kapitasi itu harus masuk ke kas daerah sebagai pendapatan daerah memang dananya itu akan dikembalikan lagi ke Dinas Kesehatan sebagai anggaran kerja tahun depan”. (Kepala Dinas Pendapatan Daerah, wawancara \# 20).

\section{PEMBAHASAN}

Hasil penelitian mengenai pemahaman bidan terhadap sistem jaminan kesehatan nasional menunjukkan bahwa sebagian besar bidan menyatakan sudah mengetahui sistem jaminan kesehatan nasional secara umum namun belum secara lebih dalam 
mengetahui tentang sistem jaminan kesehatan nasional, khususnya yang berkaitan dengan pelayanan kebidanan dan neonatal.

Secara umum pengetahuan tentang sistem jaminan kesehatan nasional sudah cukup baik dikalangan bidan dimana jaminan kesehatan nasional dianggap sebagai penerus jaminan kesehatan sebelumnya, seperti jaminan kesehatan pegawai negeri (PNS), jaminan sosial tenaga kerja, jaminan kesehatan nasional, paket jaminan kelahiran dengan pembayaran premi.

Bidan memperoleh informasi tentang sistem jaminan kesehatan nasional dari berbagai sumber yaitu dari BPJS Kesehatan, FKTP (Puskesmas), Organisasi Profesi Bidan (IBI) dan dari teman-teman bidan lainnya. Meski sudah banyak pihak yang memberikan informasi tentang sistem jaminan kesehatan nasional melalui sosialisasi, namun masih ada beberapa bidan yang merasa informasi yang didapat belum cukup untuk membuat mereka paham tentang sistem jaminan kesehatan nasional. Hal ini sejalan dengan hasil penelitian Raafiah (2018) yang menyatakan bahwa sosialisasi tidak diadakan secara khusus kepada bidan, melainkan kepada masyarakat umum dan beberapa tenaga kesehatan, sosialisasi kepada bidan biasanya diadakan oleh Ikatan Bidan Indonesia (IBI) yang bekerjasama dengan BPJS Kesehatan dan dilakukan saat pertemuan rutin IBI berlangsung.

Berdasarkan hasil penelitian menunjukkan informasi sistem jaminan kesehatan nasional juga masih kurang di masyarakat sehingga membuat bidan kesulitan menjelaskan tata cara sistem jaminan kesehatan nasional kepada masyarakat. Hal ini sejalan dengan penelitian Ernawati (2019) yang menyatakan bahwa beberapa faktor yang mempengaruhi rendahnya tingkat pengetahuan masyarakat tentang JKN Kesehatan diantaranya kurangnya media informasi dan sosialisasi. Pengetahuan masyarakat tentang tata cara sistem jaminan kesehatan nasional masih minim ini perlu dicarikan solusinya secara bertahap agar masyarakat dapat mengerti dan memahami prosedur pelaksanaan sistem jaminan kesehatan nasional. Dalam menyikapi hal tersebut, kebijakan kesehatan pemerintah harus hati-hati dan cermat agar investasi yang dilakukan selama ini tidak sia-sia.

Masih kurangnya informasi tambahan yang diperlukan bagi para bidan dalam kontribusinya untuk mensukseskan penyelenggaraan sistem jaminan kesehatan nasional berkaitan dengan pelayanan kebidanan dan neonatal serta masalah ketidaktahuan masyarakat tentang prosedur pelayanan sistem jaminan kesehatan nasional perlu ada solusinya dan segera ditindak lanjuti.

Salah satu tujuan pelaksanaan jaminan kesehatan nasional dalam sistem jaminan sosial nasional adalah untuk menurunkan angka kematian ibu dan bayi sehingga akses perlindungan bagi ibu hamil melalui jaminan pembiayaan persalinan menjadi sangat penting. Berdasarkan hasil penelitian mengenai pengetahuan bidan yang masih rendah mengenai prosedur pelayanan JKN maka perlu adanya persamaan persepsi antara Badan Penyelenggara Jaminan Sosial (BPJS) Kesehatan, pemegang polis, dan organisasi profesi, untuk bertemu dan melakukan sosialisasi terintegrasi khususnya bagi para bidan. Persamaan persepsi diperlukan adanya jalinan komunikasi yang baik dan efektif agar pelayanan kesehatan dapat berjalan maksimal. Hal ini sejalan dengan pernyataan Wahyuana (2019) yang menyatakan bahwa BPJS Kesehatan merupakan asuransi kesehatan yang secara umum didasarkan pada gagasan kerja sama diantara sekelompok orang yang membentuk lembaga, organisasi atau ikatan profesi dengan kesepakatan bersama. Mengingat sistem jaminan kesehatan nasional bertujuan untuk mewujudkan kesehatan bagi semua masyarakat termasuk memberikan jaminan kesehatan bagi ibu 
dan anak dalam pelayanan kebidanan dan neonatal, maka bidan sebagai ujung tombak pelayanan sangat membantu pemerintah dalam menurunkan angka kematian ibu dan bayi.

Berdasarkan hasil penelitian mengenai program paket jaminan kelahiran atau jampersal pada sistem jaminan kesehatan nasional pada umumnya sudah diketahui oleh para bidan baik bidan di rumah sakit, Puskesmas, maupun bidan jejaring, namun pengetahuan mereka tentang sistem ini masih rendah. Bidan masih belum mengetahui prosedur serta manfaat paket jampersal secara detail, menurut bidan biaya paket jampersal sudah cukup sesuai. Selain dari kurangnya informasi, persepsi bidan tentang prosedur yang harus dilakukan, baik untuk perjanjian kerjasama maupun klaim juga menjadi kendala bagi mereka untuk mau bekerjasama dengan BPJS. Menurut bidan, kerumitan prosedur dan klaim dana seringkali menjadi kendala dalam program-program yang diselenggarakan pemerintah, termasuk paket jaminan kelahiran. Untuk itu, perlu adanya upaya pemerintah meningkatkan kerjasama dengan bidan untuk menjadi penyedia layanan program paket jaminan kelahiran atau jampersal. Hal ini sejalan dengan pernyataan Rahayu (2019) yang menyatakan bahwa untuk menghilangkan hambatan finansial bagi ibu hamil untuk mendapatkan pelayanan pemeriksaan kehamilan, persalinan, dan pelayanan selama masa nifas, maka digulirkan kebijakan jaminan persalinan (Jampersal) sesuai Peraturan Menteri Kesehatan Republik Indonesia Nomor 61 Tahun 2017 (Kemenkes RI, 2018)

Mengenai sistem pembayaran dana non kapitasi pelayanan obstetri dan neonatal dalam sistem jaminan kesehatan nasional menurut persepsi bidan tentang tata cara klaim pemberian dana non kapitasi adalah negatif, hal ini dikarenakan aturan yang harus dijalankan bidan berupa prosedur administrasi dan verifikasi sangat rumit. Persepsi bidan terkait proses klaim dana non kapitasi juga negatif karena dari hasil analisis temuan mengenai ketepatan waktu pelaksanaan klaim yang dilakukan bidan diperoleh informasi bahwa klaim pengajuan hingga ke BPJS tidak sesuai dengan ketentuan peraturan yaitu 15 hari kerja bisa sampai berbulan-bulan dan tidak ada kepastian kapan klaim akan dibayarkan. Hal ini sejalan dengan penelitian Tarigan et al., (2020) yang menunjukkan hasil penelitian menemukan bahwa prosedur administrasi pengklaiman yang dilakukan dengan menyiapkan berkas klaim (kwitansi asli bermaterai, formulir pengajuan klaim, rekapitulasi pelayanan, fotokopi identitas BPJS, partograf, bukti pelayanan yang ditandatangani fasilitas kesehatan) dianggap masih cukup rumit, pengajuan pengklaiman BPJS Kesehatan dilakukan oleh FKTP atau klinik provider BPJS Kesehatan, namun pencairan dana hasil pengklaiman dan pencairan dana yang diberikan kepada bidan praktek membutuhkan waktu sangat lama dan tidak sesuai dengan peraturan yang telah ditetapkan.

Persepsi bidan tentang penerimaan dana non kapitasi sangat merugikan karena tidak ada dana yang diterima bidan meskipun sudah diklaim kepada BPJS Kesehatan. Hasil penelitian menemukan bahwa klaim non kapitasi tentang pelayanan kebidanan dan neonatal telah dibayarkan oleh BPJS tetapi tidak secara langsung masuk ke rekening bidan tetapi dibayarkan kepada Puskesmas. Hal ini sesuai pernyataan kepala kantor BPJS klaim non kapitasi tentang pelayanan kebidanan dan neonatal telah dibayarkan tetapi tidak secara langsung masuk ke rekening bidan namun dibayarkan kepada Puskesmas dan keseluruhan dana diserahkan ke kas daerah Pemerintah Daerah sebagai pendapatan daerah atau retribusi sesuai peraturan daerah yang ada sehingga banyak keluhan dari para bidan karena dana non kapitasi tidak pernah diterima. Dana yang masuk dalam kas daerah akan dikembalikan ke Dinas Kesehatan terkait sebagai 
anggaran kerja tahun berikutnya. Hal ini sejalan pernyataan Karim (2018) mengenai mekanisme pembayaran pelayanan kesehatan dan neonatal dana non kapitasi yang dibayarkan langsung oleh BPJS Kesehatan ke rekening JKN FKTP, selanjutnya dana yang diterima disetorkan ke kas daerah dan dapat dimanfaatkan kembali oleh FKTP. Dana non kapitasi dapat dimanfaatkan oleh faskes tingkat pertama dengan mengusulkan dalam bentuk program dan kegiatan pada Rencana Kerja dan Anggaran (RKA)Dokumen Pelaksanaan Anggaran (DPA) Satuan Kerja Perangkat Daerah (SKPD) Dinas Kesehatan. Agar penyelenggaraan JKN terlaksana secara baik, lancar, transparan dan akuntabel, pengelolaan dana tetap memperhatikan dan merujuk pada ketentuan pengelolaan keuangan yang berlaku. Agar terjadi sinergi dalam pelaksanaannya, maka pengelola Keuangan JKN menjadi satu kesatuan dengan bendahara Keuangan Dinas Kesehatan.

Penggunaan/pemanfaatan atas dana kegiatan pelayanan program Jaminan Kesehatan Nasional dilaporkan oleh FKTP ke Tim Pengelola Jaminan Kesehatan Nasional setiap bulan sesuai petunjuk yang berlaku. Tim Pengelola Jaminan Kesehatan Nasional Kabupaten kemudian menyampaikan laporan tentang penggunaan/ pemanfaatan dana kegiatan pelayanan Jaminan Kesehatan Nasional oleh FKTP dan jaringannya kepada Bupati melalui Dinas Pengelola Keuangan Daerah Kabupaten Pangkajene dan Kepulauan setiap bulannya.

Persepsi negatif bidan tentang mekanisme pembayaran pelayanan non kapitasi yang diberlakukan oleh Pemerintah Daerah dan belum adanya penerimaan dana non kapitasi sangat merugikan bagi pihak bidan yang menyediakan layanan kebidanan dan neonatal. Oleh karena itu diharapkan adanya upaya kebijakan berupa Peraturan Bupati mengenai tata hubungan kerjasama antara FKTP atau klinik provider, bidan, BPJS Kesehatan dan Pemerintah Daerah yang diformulasikan dengan baik agar menjadi dasar/pedoman pelaksanaan mekanisme pembayaran pelayanan kesehatan dan neonatal yang lebih jelas dan adil bagi bidan.

Berkenaan dengan permasalahan yang ada bidan di Puskesmas dan bidan jejaring merasa kurang adanya perhatian dan empati dari pemerintah terkait hak bidan tentang pendanaan dana non kapitasi untuk layanan kebidanan dan neonatal dalam penyelenggaraan sistem jaminan kesehatan nasional. Di sini pembayaran dana sudah diberikan oleh BPJS namun dalam hal kebijakan daerah, tata cara pembayaran harus diberikan kepada pemerintah daerah melalui Puskesmas sebagai pendapatan daerah dan tidak diberikan langsung kepada bidan sebagai pemberi pelayanan kesehatan sehingga sampai saat ini tidak pernah diterima oleh bidan, meskipun mereka telah mengklaim pekerjaan mereka yang telah diverifikasi oleh BPJS. Ketidakadilan ini dirasakan bidan dan merugikan bidan karena membantu persalinan tidak mudah karena dua nyawa harus diurus, ibu dan bayi. Hal ini dikhawatirkan akan menurunkan kepuasan kerja, kinerja dan motivasi bidan untuk bekerja dan mendukung menurunkan angka kematian ibu dan bayi di Kabupaten $X$.

Namun secara regulasi dan peraturan perundang-undangan, Pemerintah Daerah Kabupaten $\mathrm{X}$ belum mengeluarkan peraturan daerah tentang pengelolaan dan pemanfaatan dana non kapitasi untuk sistem jaminan kesehatan nasional pada FKTP, klinik dan jaringannya. Padahal, agar penyelenggaraan teknis sistem jaminan kesehatan nasional dapat berjalan dengan baik, diperlukan sejumlah peraturan pemerintah, baik peraturan nasional maupun daerah untuk menyesuaikan perkembangan pelayanan di era jaminan kesehatan nasional sehingga implementasi bisa lebih baik. 
Karena belum adanya regulasi dan petunjuk teknis pengelolaan dan penggunaan dana non kapitasi untuk penyelenggaraan sistem jaminan kesehatan nasional di fasilitas kesehatan tingkat pertama dan jaringannya di Kabupaten X, maka terjadi ketidakpastian dalam pengelolaan keuangan dana untuk kebidanan dan pelayanan kesehatan neonatal yang menyebabkan kerugian dan ketidakadilan bagi bidan sebagai pemberi pelayanan kesehatan. Kondisi seperti ini dalam jangka panjang dapat mempengaruhi kinerja dan motivasi bidan untuk menurunkan angka kematian ibu dan bayi di Kabupaten $\mathrm{X}$, Indonesia.

\section{SIMPULAN}

Kesimpulan yang dapat diambil dari penelitian ini adalah masih banyak pembenahan yang perlu dilakukan terhadap kebijakan dan regulasi sistem jaminan kesehatan nasional, baik di tingkat pusat maupun daerah, agar pelaksanaannya dapat berjalan dengan baik yang nantinya akan, pada gilirannya, secara signifikan menurunkan angka kematian ibu dan bayi.

\section{SARAN}

Untuk memaksimalkan dampaknya ke depan, perlu dilakukan sosialisasi dan pemeriksaan ulang peraturan penyelenggaraan sistem jaminan kesehatan nasional.

\section{DAFTAR PUSTAKA}

Basuki, E. W., Sulistyowati \& Herawati, N. R. (2016). Implementasi Kebijakan Jaminan Kesehatan Nasional oleh BPJS Kesehatan di Kota Semarang. Diponegoro Journal of Social and Political Of Science, pp. 1-11. Available at: http://ejournal-s1.undip.ac.id/index.php/

Ernawati, C. T. \& Uswatul, D. (2019). Hubungan Kepesertaan JKN Mandiri dengan Pendapatan, Pengetahuan, Persepsi, Akses, dan Kepercayaan Masyarakat Suku Sakai di Desa Petani Kecamatan Mandau Kabupaten Bengkalis Tahun 2018. Jurnal Kebijakan Kesehatan Indonesia: JKKI, 8(1), 25-29. https://jurnal.ugm.ac.id/jkki/article/view/45017

Karim, M. I. T., Moenta, A. P. \& Riza, M. (2018). Implementasi Kebijakan Pemerintah Daerah di Bidang Kesehatan Masyarakat Melalui Jaminan Kesehatan Nasional. Amanna Gappa, 26(1), 53-63. Available at: muh.iman.mi98@gmail.com.

Kemenkes RI (2018). Peraturan Menteri Kesehatan Republik Indonesia Nomor 61 Tahun 2017 Tentang Petunjuk Teknis Penggunaan Dana Alokasi Khusus Non Fisik Bidang Kesehatan Tahun Anggaran 2018. Jakarta

Larasati, T., Bachtiar, H., \& Muhammad, S. (2019). Analisis Faktor yang Berhubungan dengan Keikutsertaan Bidan Praktek dalam Pelayanan Kebidanan pada Program Badan Penyelenggara Jaminan Sosial di Kabupaten Pasaman Barat Tahun 2018. Jurnal Kesehatan Andalas, 8(4), pp. 192-201. DOI: 10.25077/jka.v8i4.1140

Raafiah, A. (2018). Faktor Individual dan Struktural pada Kepuasan Kerja Bidan Era Jaminan Kesehatan Nasional. HIGEIA Journal of Public Health Research and Development, 2(4), 520-530. doi: https://doi.org/10.15294 /higeia.v2i4.23915

Rahayu, E. (2019). Faktor-Faktor yang Mempengaruhi Pemanfaatan Program Jaminan Persalinan (Jampersal) oleh Ibu di Wilayah Kerja Puskesmas Seimbu Kabupaten Landak. Skripsi. Universitas Muhammadiyah Pontianak. Retrieved July 10, 2020 from: http://repository.unmuhpnk.ac.id/1000/ 
Tarigan, N., Silaen, M., \& Lubis, R. (2020). Analisis Kebijakan Hubungan Klinik Provider BPJS Kesehatan dan Praktek Mandiri Bidan Sebagai Jejaring. Jurnal Prima Medika Sains, 2(1), 18-23. doi: 10.1616/jpms.v2i1.974

Wahyuana, S. P. (2019). Persyaratan Sepihak dalam Proses Kepesertaan Badan Penyelenggara Jaminan Sosial Perspektif Tokoh Nahdlatul Ulama dan Muhammadiyah Kota Batu. Skripsi. Universitas Islam Negeri Maulana Malik Ibrahim Malang. Retrieved July 10, 2020 from: http://etheses.uinmalang.ac.id/13487/ 